\title{
Correction to: Non-linear weight adjustment in adaptive gamma correction for image contrast enhancement
}

Debapriya Sengupta $^{1,2}$ D $\cdot$ Arindam Biswas $^{1} \cdot$ Phalguni Gupta $^{3}$

Published online: 8 November 2020

(C) Springer Science+Business Media, LLC, part of Springer Nature 2020

Correction to: Multimedia Tools and Applications (2020) https://doi.org/10.1007/s11042-020-09583-1

Figure 16 in the original publication was incomplete. The original article has been corrected.

Publisher's note Springer Nature remains neutral with regard to jurisdictional claims in published maps and institutional affiliations.

Debapriya Sengupta

debapriya_20oct@yahoo.co.in

Arindam Biswas

barindam@gmail.com

Phalguni Gupta

pg@gla.ac.in

1 Indian Institute of Engineering Science and Technology, Howrah, India

2 National Institute of Technical Teachers' Training and Research, Kolkata, India

3 GLA University, Mathura, India 